\title{
Effect of Carbonation on Long-Term Measurements of Sorption Isotherms of Autoclaved Aerated Concrete
}

\author{
Olga Koronthalyova ${ }^{1, a^{*}}$ and L'ubomír Bagel ${ }^{1, b}$ \\ ${ }^{1}$ Institute of Construction and Architecture Slovak academy of Sciences, Dubravska c 9, \\ 84503 Bratislava, Slovakia \\ ausarkoro@savba.sk, busarbage@savba.sk \\ ${ }^{*}$ corresponding author
}

Keywords: autoclaved aerated concrete, carbonation, pore structure water vapour adsorption.

\begin{abstract}
The laboratory measurement of water vapour adsorption/desorption curves is a standard tool for determination of the moisture capacity of porous building materials in hygroscopic region. However, in case of cementitious materials, additional processes like carbonation can occur during the measurement. Generally, process of carbonation affects the pore structure of the material and results in an increase of its bulk density. Therefore, for determination of correct sorption curves the carbonation caused bulk density increase has to be eliminated. In this work the both mentioned effects of carbonation on the measured water vapour sorption isotherm were quantified for autoclaved aerated concrete (AAC). Within the monitored 9-year period, the carbonation caused noticeable changes in microstructure of the tested AAC samples, namely a decrease of the specific surface area of pores and the portion of very small pores. These microstructure changes affected the moisture storage capacity too - the obtained equilibrium moisture contents of the partly carbonated $\mathrm{AAC}$ were lower than the ones of the AAC close to the original state. It was also confirmed that in case of continuous measurement of the water vapour sorption curve the carbonation induced bulk density increase could result in an overestimation of the equilibrium moisture contents.
\end{abstract}

\section{Introduction}

The water vapour adsorption/desorption curves are important material parameters defining the moisture capacity of porous building materials in hygroscopic region. Particularly for building materials in envelope structures that are exposed to changing boundary conditions the actual moisture capacity involves also the possible hysteretic behaviour of the material.

Carbonation of the autoclaved aerated concrete (AAC) occurs if AAC exposed to influence of atmospheric carbon dioxide in the presence of moisture. In this process the main binding mineral of AAC - tobermorite reacts with carbon dioxide and is decomposed to silica-gel and calcium carbonate [1]. This results not only in change of mineral composition of AAC but also in change of AAC microstructure. Consequently, changes of other important properties as strength, shrinkage or moisture storage can arise. Under natural conditions, the process of carbonation is slow due to the slowness of the carbon dioxide diffusion at relative small concentration of carbon dioxide in air $(0.03-0.07$ vol.\%). Therefore, the carbonation is often studied under accelerated conditions, using increased carbon dioxide concentrations. However, using results of the accelerated tests is not straightforward - some material parameters can be changed in a different way under accelerated conditions compared to the natural conditions [1].

The previous works regarding the AAC carbonation under natural conditions have showed an increase of bulk density as well as microstructure changes, especially a decrease of the specific surface area of pores $[1,2]$. However, works dealing with an effect of carbonation on the moisture capacity are relative rare.

In this work, the effect of natural carbonation on the measured water vapour adsorption/desorption loop is quantified for one type of AAC. Besides, the significance of the effect 
of the carbonation induced bulk density increase during the continuous sorption measurement is evaluated.

\section{Materials and methods}

The tested material is AAC (produced by Hebel) with lime-cement binder and sand filler.

The material was characterised by the following basic parameters: bulk density, total open porosity and capillary moisture content. The bulk density was calculated from volume and mass of the dried out samples (oven drying at $105^{\circ} \mathrm{C}$ ). The total open porosity was obtained from a water saturation test and mercury intrusion porosimetry. The capillary moisture content was achieved from one dimensional time-controlled capillary water uptake experiment, in which an oven-dry sample is allowed to absorb liquid water from a free water plane [3].

Pore structure parameters - pore size distribution and specific surface area were determined by mercury intrusion porosimetry (MIP) and nitrogen adsorption respectively. These measurements were repeated after some time of the samples exposure in order to check the carbonation induced changes of pore structure.

The MIP measurements were done on the high-pressure porosimeter (Quantachrome). The device enables to determine pores with the radius ranging from $1.83 \mathrm{~nm}$ up to $0.53 \mathrm{~mm}$. The MIP measurement was carried out on the fraction of broken dried (up to $105^{\circ} \mathrm{C}$ ) samples.

Nitrogen adsorption measurements were performed with the volumetric ASAP2400 instrument, enabling isotherms to be obtained in the $0.01-0.98$ relative pressure range. Prior to the measurement the samples were degassed overnight at $150{ }^{\circ} \mathrm{C}$ and $2 \mathrm{~Pa}$. The mass of tested samples was of about $7 \mathrm{~g}$. The specific surface area of pores was determined by the Brunauer Emmett and Teller (BET) method. The pore size distribution was calculated from nitrogen desorption by the Barret - Joyner - Halenda method [4].

The water vapour sorption curves were measured by standard gravimetric desiccator method, which consists in conditioning the samples in desiccators under constant relative humidity (RH) and temperature $\left(23^{\circ} \mathrm{C}\right)$ until the static equilibrium is achieved [5]. The desiccators were placed in an air conditioned test-room with the temperature controlled at $22.5 \pm 0.5{ }^{\circ} \mathrm{C}$. The measurements were done for seven RH values: $11.3 \%, 33 \%, 53 \%, 75 \%, 85 \%, 94 \%$ and $98 \%$ that were obtained using the saturated salt solutions according to the standard recommendations [5]. The tested samples had a cuboids shape with the mass from 13 to $32 \mathrm{~g}$. Drying of the specimens was performed at $105{ }^{\circ} \mathrm{C}$ and weighing was carried out by means of electronic scales with the accuracy of $0.001 \mathrm{~g}$. The sorption measurements were done on at least three specimens. In the analysis the mean values of these measurements were used. Desorption curves were measured from equilibrium moisture content at relative humidity of $98 \%$.

In order to enable a verification of the possible bulk density changes of the specimens, the separate sets of specimens per particular RH level were used as it is recommended in [6]. Besides, a continuous measurement of the desorption branch was carried out. The first set of the sorption measurements were done for samples after their 1.9 years of exposure in laboratory conditions. The comparative sorption measurements were carried out on samples exposed for 7 years. In between, the specimens were storied in laboratory room with the air temperature varying from 18.0 to $25^{\circ} \mathrm{C}$ and RH varying from 40 to $60 \%$ or were undergone to other sorption tests.

\section{Results and discussion}

The basic material parameters of the tested AAC are shown in Table 1. These parameters were determined on specimens exposed to laboratory conditions for one year.

The important criterion indicating the presence of carbonation of AAC is advancing bulk density increase [2]. Generally, the actual time course of the bulk density changes reflects the AAC type, the parameters of the surroundings (carbon dioxide concentration, relative humidity) as well as dimensions and shape of sample [2]. 
Table 1: Basic material parameters of tested AAC

\begin{tabular}{cccc}
\hline $\begin{array}{c}\text { Bulk density } \\
{\left[\mathrm{kg} / \mathrm{m}^{3}\right]}\end{array}$ & $\begin{array}{c}\text { Open porosity } \\
\text { water saturation }[-]\end{array}$ & $\begin{array}{c}\text { Open porosity } \\
\text { MIP [-] }\end{array}$ & $\begin{array}{c}\text { Capillary saturation moisture } \\
\text { content }\left[\mathrm{kg} / \mathrm{m}^{3}\right]\end{array}$ \\
\hline 512 & 0.8 & 0.53 & 270 \\
\hline
\end{tabular}

The observed time course of the mass increase of samples is shown in Fig. 1. The mass increase was calculated using the mass of the samples oven dried at temperature of $105{ }^{\circ} \mathrm{C}$. Here, as well as in the following analysis the term 'time of exposure' means the sum of all periods when samples were in laboratory room, in desiccators or in oven.

After 8-year period of exposure the obtained mass increase values range from 1.5 to $2.3 \%$. It is in agreement with the previous work [2] where for similar AAC materials stored for 9 years in laboratory room the mass increase due to carbonation was between 1.3 and $3.1 \%$. The differences between particular samples can be explained by different samples dimensions, different surroundings (namely different RH in desiccators) and possible material non-homogeneity.

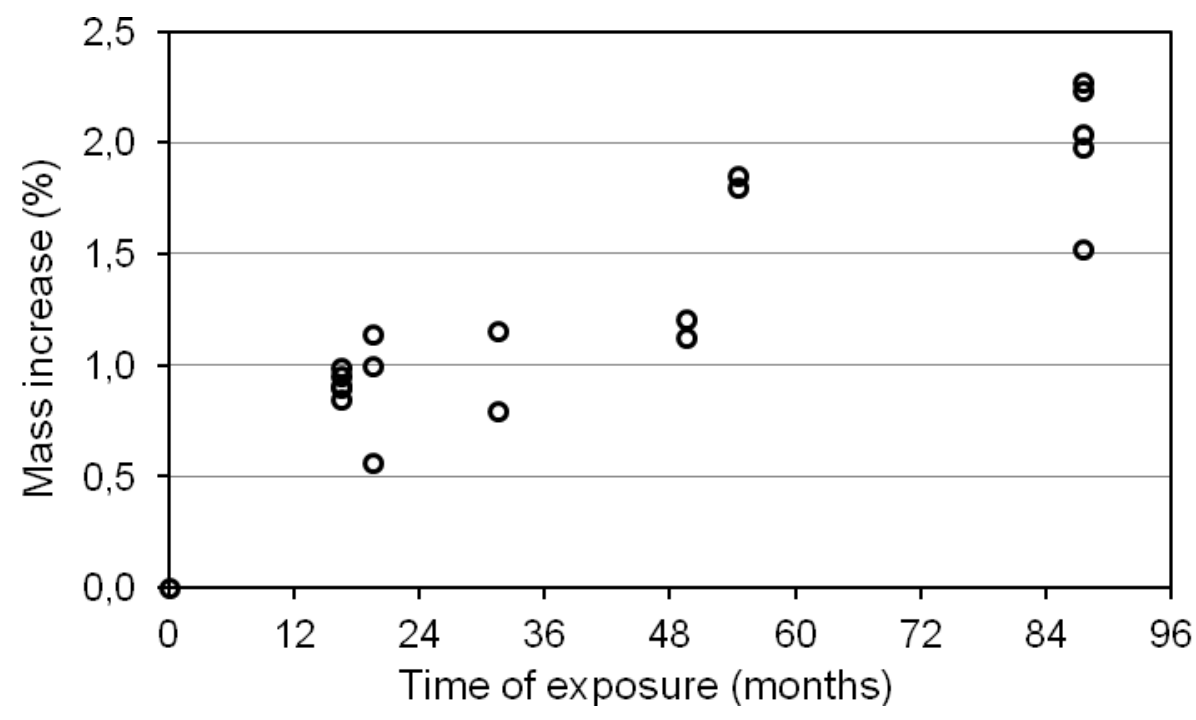

Fig. 1: Mass increase of the tested AAC specimens during 8-year period

In Fig. 2 the MIP pore size distribution of the original AAC and the AAC after 9 years of exposure is compared. For the exposed AAC, a decrease of the total pore volume can be observed. The decrease took place in the pore range with radii from 2 to $20 \mathrm{~nm}$. Similar result was reported in [1], where for naturally carbonated AAC at 33\% degree of carbonation the total pore volume decrease of about $13 \%$ was found out in the same pore range.

In Figs. 3-4 the changes of the AAC microstructure caused by the carbonation are illustrated. Fig. 3 shows monitored changes of the specific surface area (SSA) of pores. During the 13-year period the SSA decreased by more than $40 \%$. The noticed SSA decrease correspondes to the previously published results [1] where the original SSA value of $20 \mathrm{~m}^{2} / \mathrm{g}$ decreased to value of about $11 \mathrm{~m}^{2} / \mathrm{g}$ after 30 years of carbonation under natural conditions. Fig. 4 illustrates the effect of exposure duration on the pore size distribution. A decrease of the portion of pores with small radii (lower than $30 \mathrm{~nm}$ ) is evident. 


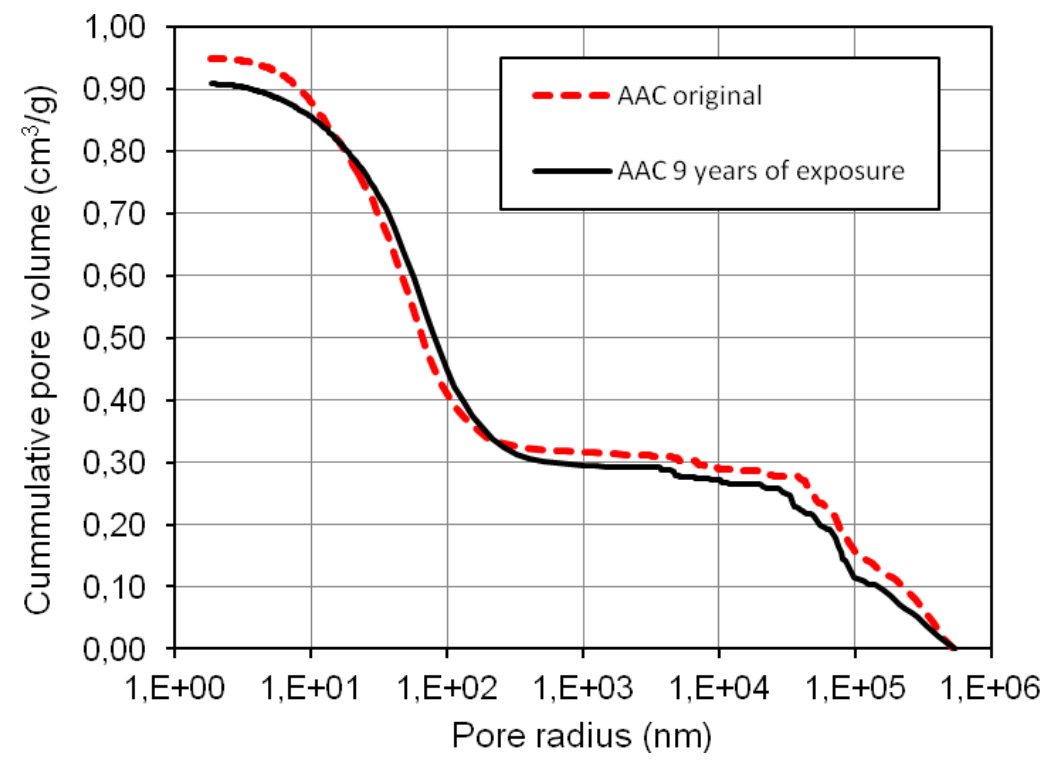

Fig.2: Comparison of the MIP pore size distribution of the original AAC and the AAC after 9 years of exposure

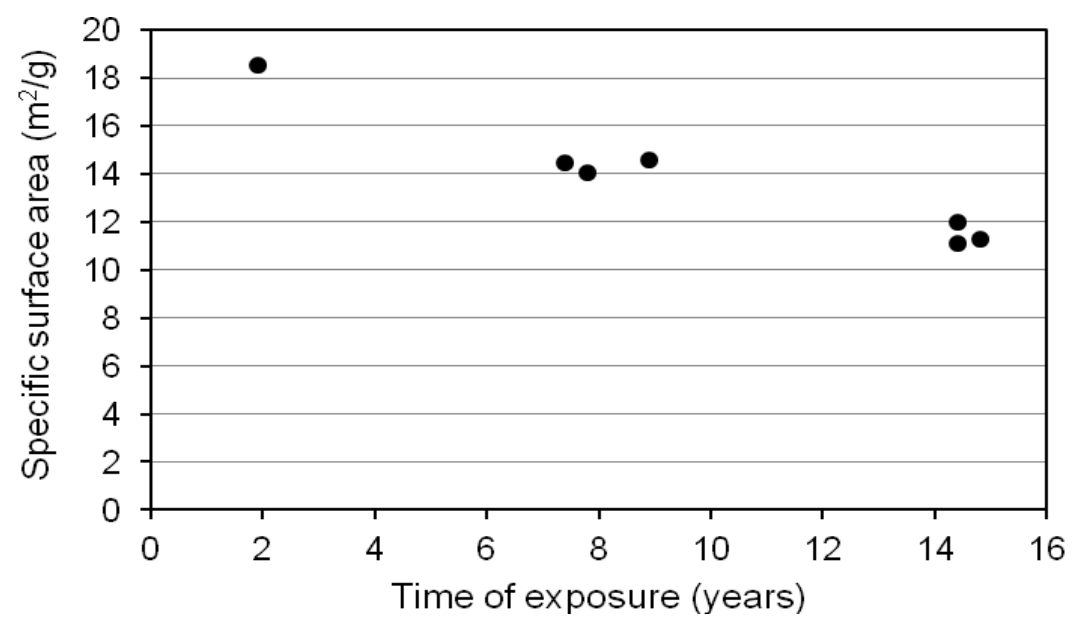

Fig. 3: BET specific surface area of pores vs. time of exposure

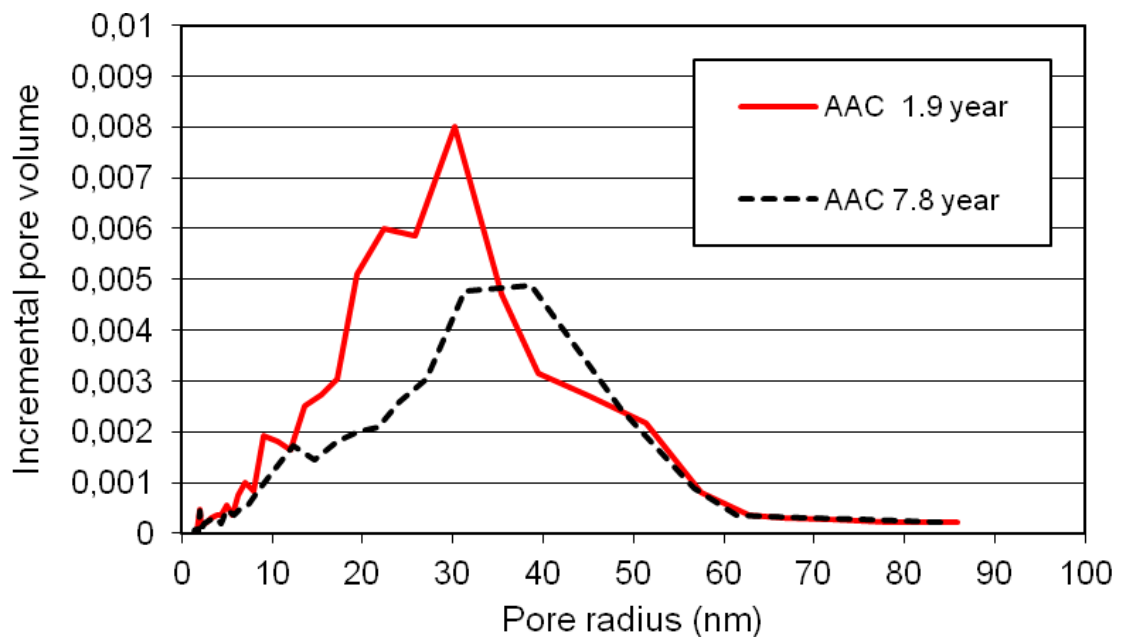

Fig. 4: Effect of the exposure duration the pore size distributions determined by nitrogen desorption. 

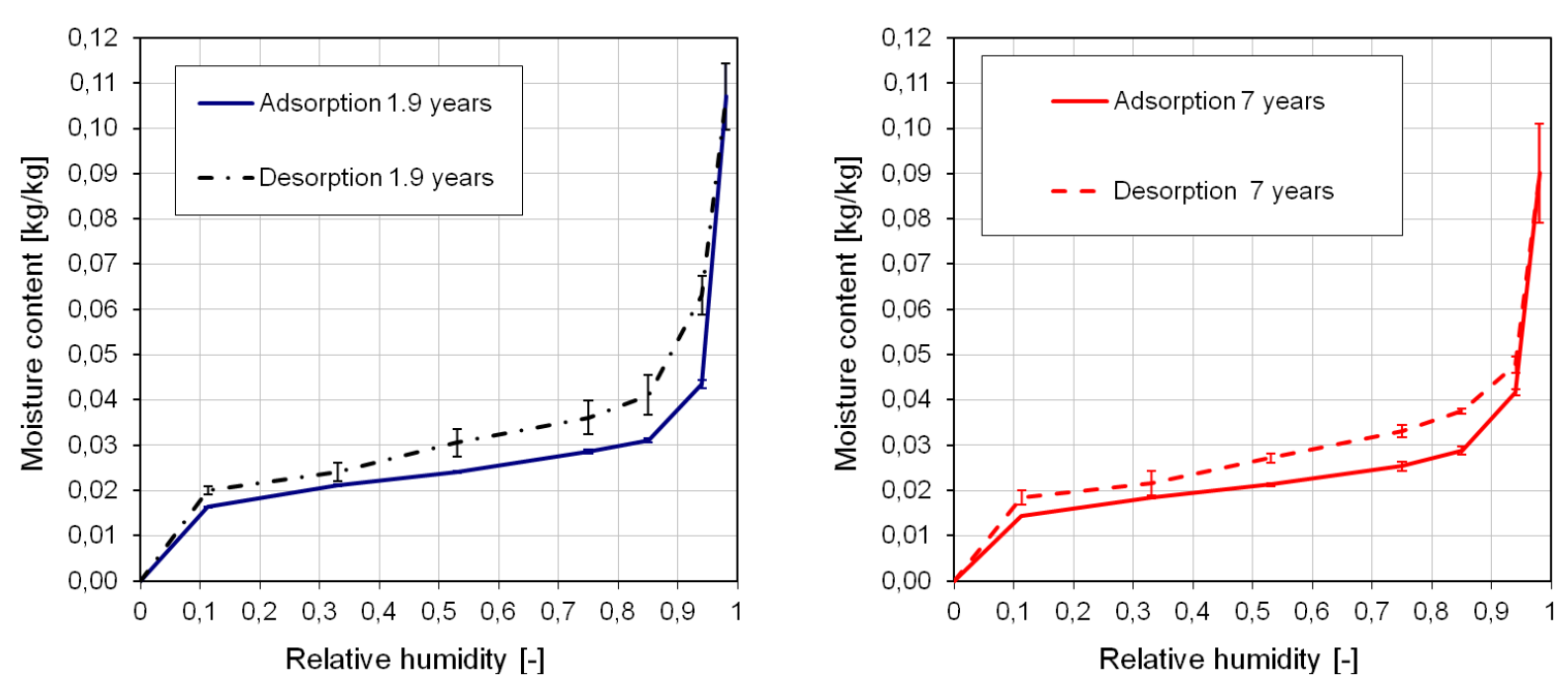

Fig. 5: Water vapour adsorption/desorption curves of the tested AAC. Error bars represent standard deviations. Left: AAC after 1.9-year exposure, right: AAC after 7-year exposure

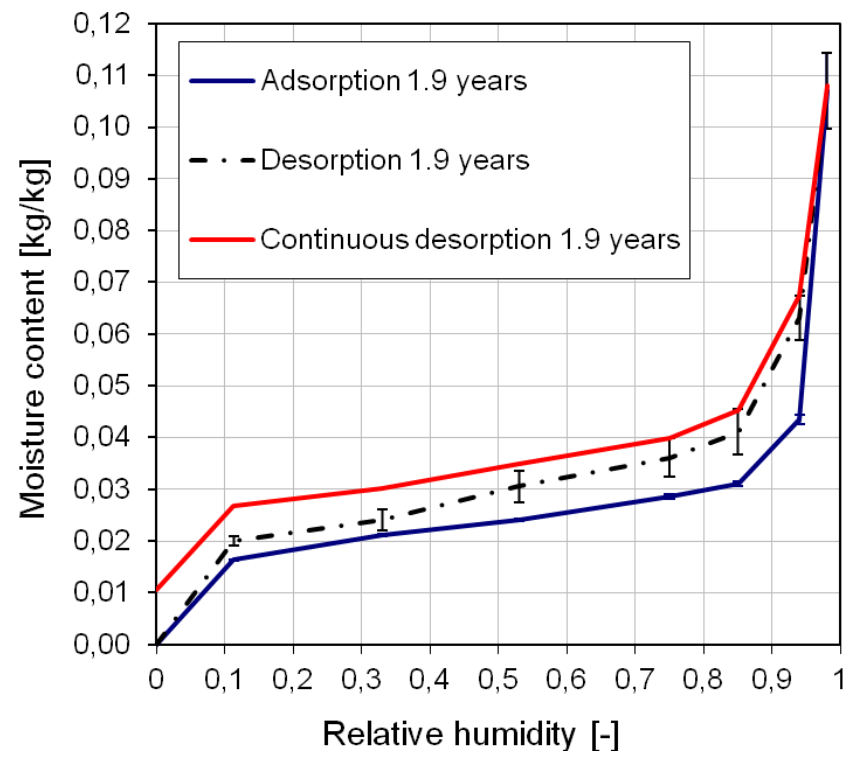

Fig. 6: Continuously measured water vapour desorption branch the tested AAC compared with the adsorption/desorption curves measured separately per each RH level

The noticed changes of microstructure resulted in changes of the measured adsorption/desorption loop (Fig. 5). Equilibrium moisture contents of the samples after 7-year exposure are shifted to the lower values. This shift is significant especially in range of higher RH. Taking into account the obtained relation between the time of exposure and specific surface area of pores (Fig. 3) some further decrease of equilibrium moisture contents can be expected.

The effect of the carbonation induced mass increase on the measured values of equilibrium moisture content for the case of continuous measurement is illustrated in Fig. 6. The measurement of the whole desorption branch (from $\mathrm{RH}$ of 98\%) took about 14 months. Within this period the total mass increase of measured samples achieved 1.05\%. As can be seen from Fig. 6 the continuous measurement overestimates the present hysteretic effects. This effect could be of importance especially in case of measurement of AAC samples with relative short time of exposure, where more significant mass increase can be expected (cf. Fig. 1). 


\section{Conclusions}

The effects of carbonation induced changes of microstructure and bulk density on the measured water vapour adsorption/desorption loop were quantified for one type of autoclaved aerated concrete.

Within the monitored 9-year period, the carbonation has caused noticeable changes in microstructure of the tested AAC samples, namely a decrease of the specific surface area of pores as well as the portion of very small pores. These microstructure changes affected the moisture storage capacity as well - the obtained equilibrium moisture contents of the partly carbonated AAC were lower than the ones of the AAC close to the original state.

The continuous measurement of the desorption branch confirmed that if the carbonation involved mass changes of the tested AAC were not eliminated the obtained equilibrium moisture contents were overestimated. This effect can be of importance especially in case of measurement of AAC samples with relative short time of exposure, where more significant mass increase can be expected.

\section{Acknowledgements}

This research was supported by the Scientific Grant Agency VEGA (Grant No. 2/0145/13).

\section{References}

[1] F. Matsushita, A. Yoshimichi, S. Shibata, Microstructure changes in autoclaved aerated concrete during carbonation under working and accelerated conditions. Journal of Advanced Concrete Technology 2 (2004) 121-129.

[2] K. Hanečka, O. Koronthályová, P. Matiašovský, The carbonation of autoclaved aerated concrete. Cement and Concrete Research 27 (1997) 589-599.

[3] S. Roels, J. Carmeliet, H. Hens, O. Adan, H. Brocken, R. Cerny, Z. Pavlik, C. Hall, K. Kumaran, L. Pel, R. Plagge, Interlaboratory Comparison of Hygric Properties of Porous Building Materials. J. Build. Phys. 27 (2004) 307-325.

[4] K. K. Aligizaki, Pore Structure of Cement-Based Materials, Taylor\& Francis, London and New York, 2006.

[5] EN ISO 12571:2000: Hygrothermal performance of building materials and products Determination of hygroscopic sorption properties (2000).

[6] K. E. Wilkes, J. A. Atchley, P. W. Childs, A. Desjarlais, Effects of drying conditions, phase transformations, and carbonation reactions on measurements of sorption isotherms of building materials. Journal of ASTM International, 4 (2007) No.8. 